EGU21-702

https://doi.org/10.5194/egusphere-egu21-702

EGU General Assembly 2021

(c) Author(s) 2021. This work is distributed under

the Creative Commons Attribution 4.0 License.

\title{
The impact of urbanization and rapid population growth on the groundwater regime in Dhaka city, Bangladesh
}

\author{
Mazeda Islam ${ }^{1,2}$, Marc Van Camp ${ }^{1}$, Delwar Hossain², Md. Mizanur Rahman Sarker ${ }^{1,2}$, Shahina \\ Khatun $^{3}$, and Kristine Walraevens ${ }^{1}$ \\ ${ }^{1}$ Ghent University, Department of Geology, Ghent, Belgium (Mazeda.Islam@UGent.be) \\ ${ }_{2}^{2}$ Jahangirnagar University, Department of Geological Sciences, Dhaka, Bangladesh (mazeda@juniv.edu) \\ ${ }^{3}$ Dhaka Water and Sewerage Authority, Dhaka, Bangladesh
}

Dhaka city with an area of about $306 \mathrm{Km}^{2}$ and a population of more than 20 million is located in the central part of Bangladesh. Immense and prolonged groundwater abstraction due to rapid unplanned urbanization and population blast in this city have led to significant decline in groundwater level in the last three decades. 78\% of the supplied water comprises groundwater from the Dupi Tila Sandstone aquifer system. Hydrogeological and geophysical data aided to the delineation of three different aquifers (based on lithology): Upper Dupi Tila aquifer (UDA), Middle Dupi Tila aquifer (MDA) and Lower Dupi Tila aquifer (LDA). The evaluation of long-term hydrographs, piezometric maps and synthetic graphical overviews of piezometric trends in both the UDA and MDA depicts that the rate of dropping of groundwater level (GWL) is very substantial. Massive pumping in the city has altered its natural hydrologic system. The groundwater level has dropped on average $2.25 \mathrm{~m} /$ year and $2.8 \mathrm{~m} /$ year in UDA and MDA, respectively, in the whole city in 2018 , whereas the average rate of decline in the center of the depression cone during this time was $4.0 \mathrm{~m} /$ year and $5.74 \mathrm{~m} /$ year respectively. Presently, the groundwater level elevation has declined to levels lower than -85 and $-65 \mathrm{~m}$ PWD in UDA and MDA, respectively. The changes in pattern and magnitude of depression cones in UDA and MDA are directly associated with the city expansion and number of deep tube wells installed over a certain period in particular parts of the city. The depletion of GWL from 1980 to 2018 is very notable. There is only limited vertical recharge possible in the UDA and MDA as they are semi-confined aquifers, and only lateral flow mostly in the UDA and MDA from the surroundings is to be expected. In this regard the long-term management of groundwater resources in Dhaka city is urgently needed, otherwise the condition may go beyond control.

Key words: Groundwater abstraction, city expansion, hydrographs, piezometric maps, GWL decline, depression cone. 